\title{
COMMUNITY ASSEMBLY IN EXPERIMENTAL GRASSLANDS: SUITABLE ENVIRONMENT OR TIMELY ARRIVAL?
}

\author{
Rasmus Ejrnas, ${ }^{1,4}$ Hans Henrik Bruun, ${ }^{2}$ and Bente J. Graae ${ }^{3}$ \\ ${ }^{1}$ Department of Wildlife Ecology and Biodiversity, National Environmental Research Institute, Grenåvej 12, 8410 Rønde, Denmark \\ and Arctic Station, University of Copenhagen, P.O. Box 504, 3953 Qeqertarsuaq, Greenland \\ ${ }^{2}$ Lund University, Section of Plant Ecology and Systematics, Ecology Building, 22362 Lund, Sweden \\ ${ }^{3}$ Climate Impacts Research Centre, Department of Ecology and Environmental Science, Umeà University, \\ Box 62, S-98107 Abisko, Sweden
}

\begin{abstract}
It is hard to defend the view that biotic communities represent a simple and predictable response to the abiotic environment. Biota and the abiotic environment interact, and the environment of an individual certainly includes its neighbors and visitors in the community. The complexity of community assembly calls forth a quest for general principles, yet current results and theories on assembly rules differ widely.

Using a grassland microcosm as a model system, we manipulated fertility, disturbance by defoliation, soil/microclimate, and arrival order of species belonging to two groups differing in functional attributes. We analyzed the outcome of community assembly dynamics in terms of species richness, invasibility, and species composition. The analyses revealed strong environmental control over species richness and invasibility. Species composition was mainly determined by the arrival order of species, indicating that historical contingency may change the outcome of community assembly. The probability for multiple equilibria appeared to increase with productivity and environmental stability. The importance of arrival order offers an explanation of the difficulties in predicting local occurrences of species in the field.

In our experiment, variation in fertility and disturbance was controlling colonization with predictable effects on emergent community properties such as species richness. The key mechanism is suggested to be asymmetric competition, and our results show that this mechanism is relatively insensitive to the species through which it works. While our analyses indicate a positive and significant correlation between richness and invasibility, the significance disappears after accounting for the effect of the environment.

The importance of arrival order (historical contingency) and environmental control supports the assumption of the unified neutral theory that different species within a trophic level can be considered functionally equivalent when it comes to community assembly. However, our results indicate that variation in asymmetric competition is the key factor determining the richness of the resulting communities, and this is far from neutral.
\end{abstract}

Key words: diversity; invasibility; multiple equilibria; niche differentiation; neutral theory; richness; species pool; vegetation.

\section{INTRODUCTION}

Despite a long tradition of understanding communities as deterministic biotic responses to the environment, historical processes receive increasing attention (Svenning et al. 2004, Ozinga et al. 2005). Not only does history constrain the number and identity of species available for assembly (Zobel 1997), but the biota itself modifies the environment, and early colonizers may thus either facilitate or impede the colonization of later arriving species. Accordingly, variation in colonization sequence may give rise to different communities in similar sites (Diamond 1975, McCune and Allen 1985, Chase 2003).

Manuscript received 10 August 2005; revised 4 November 2005; accepted 22 November 2005. Corresponding Editor: T. J. Stohlgren.

${ }^{4}$ E-mail: rej@dmu.dk
It is increasingly acknowledged that plants modify the environment by depleting resources and changing the microclimate and the cycling of nutrients by decomposers (Davis et al. 2000). It is recognized as well that the presence and composition of other trophic levels may have significant effects on the assembly of vegetation (Grime et al. 1987, de Deyn et al. 2003). This complexity of community assembly calls for a demonstration of consistent principles for generalization and prediction, a task that is further challenged by the ongoing scientific debate over the relative importance of historical, biotic, and abiotic factors in community assembly (Hubbell 2001, Kennedy et al. 2002, Weiher et al. 2004).

It is well established that richness, productivity, invasibility, and species composition vary along environmental gradients in site fertility and disturbance intensity (Grime 1979, Huston 1994). The interpretation varies, however, from the humped-back model predict- 
ing that increased asymmetric competition along gradients in productivity invokes a decline in species richness (Grime 1973a, b, 1979), over the niche differentiation model predicting that diversity promotes productivity and prevents invasion (Spehn et al. 2005), to a neutral explanation of community assembly as a mere reflection of historically determined species pools and physically determined plant community structure (Hubbell 2001, Aarssen 2004).

The humped pattern is frequently observed (Mittelbach et al. 2001), and there is experimental support for increasing competitive asymmetry with increasing productivity (Keddy et al. 1997). Lately, colonization and establishment have become focal points for research (Foster et al. 2002, Stevens et al. 2004), and the results have suggested that high productivity should be negatively related to invasibility and richness, whereas invasibility and richness should be positively correlated without direct causality (Foster et al. 2002).

Similarly to the fertility gradient, variation in disturbance has been reported to invoke a unimodal response in richness, with a peak at intermediate disturbance (Grime 1973b, Connell 1978). High diversity at intermediate disturbance is caused by the increased availability of unused resources (light, water, nutrients) following disturbances that promote germination and establishment of seedlings (Davis et al. 2000). Declining richness at high intensities of disturbance follows from accelerated seedling mortality, eventually exceeding germination.

While the hypothesized causality of the humped-back model and intermediate disturbance hypothesis goes from environment to biotic response, evidence is accumulating that plant diversity itself may have significant and consistent positive effects on productivity and resistance to invasion (Spehn et al. 2005). The main cause is believed to be niche differentiation. The more species present, the more niches will be filled, resulting in higher resource use efficiency, increased productivity, and less opportunity for invasion.

The above-mentioned theories assume causality of processes in present time, whereas the neutral theory (Hubbell 2001, 2005) and the species pool theory (Zobel 1997) challenge the scientific community with the claim that community assembly and emerging diversity may be explained by historical processes including speciation, migration, and extinction. Although a joint effect of environment and species pools is often acknowledged (Grime 1979, Zobel 1997), some researchers have suggested that local variation in diversity may be explained parsimoniously by historical species pools and by the size of individuals, setting an upper limit to the density of species (Pärtel et al. 1996, Hubbell 2001, Aarssen 2004). The idea that historical contingency may have a decisive and lasting effect on species composition (Chase 2003) also emphasizes the relative importance of historical contingency over ecological determinism.
The objective of the present study was to investigate the extent to which (1) species richness, (2) number of invading species, and (3) species composition can be predicted from the environment and the arrival order of two species groups differing widely in ecological adaptations and success in the current landscape. In doing so, we wanted to advance predictive community ecology and address the relative importance of local environment, niche differentiation, and neutral effects for community assembly.

In order to increase the relevance of our study, we have chosen environmental treatments and levels (fertility and disturbance by defoliation) relevant to some of the major land use changes that have affected the diversity of European grasslands over the last decades, namely eutrophication and the cessation of grazing. The generality of the experiment was extended by applying the treatments in two different soil/climate settings.

\section{Material and Methods}

A three-year grassland succession in outdoor microcosms was established on a research field in Kalø, Eastern Jutland, Denmark (see Plate 1). The region has a temperate climate with a mean temperature for January and July of $0.2^{\circ}$ and $16.2^{\circ} \mathrm{C}$, respectively, and a mean annual precipitation of $640 \mathrm{~mm}$. The design was a factorial experiment with 10 replicates, testing the effect of all 16 combinations of four two-level treatments: contrasting soil/climate, fertilization, repeated defoliation, and colonization sequence. The experiment was established 20 May 1998 and maintained until 25 July 2000 . We used solid plastic boxes $(37 \times 27 \times 28 \mathrm{~cm})$ drained through five holes in the bottom and placed on a plastic membrane over $30 \mathrm{~cm}$ of sand (Appendix A). The area between the boxes was covered with wood chips up to $5 \mathrm{~cm}$ from box edges to suppress weeds around boxes and prevent the soil from drying out. In each of two locations (soil/climate treatment) the microcosms were placed in two rows with an inter-box distance of $70 \mathrm{~cm}$. Each double row was divided into five blocks containing two randomly distributed replicates of each treatment in order to pursue and correct for unintentional withinlocation environmental variability.

\section{Growth medium}

We used wet mineral sand from a local gravel pit as substrate and applied a common microbiotic inoculum to all microcosms. We collected $10 \mathrm{~kg}$ of soil and roots from the upper $5 \mathrm{~cm}$ of three different biotopes: a fertile road verge; an ungrazed, seminatural grassland on a calcareous mixed glacial till; and a grazed, seminatural, moderately acidic grassland on siliceous soil. The roots were washed free of sand and soil, cleaned for stolons, air dried in room temperature, and thoroughly minced. The soil was mixed and washed through a $125-\mu \mathrm{m}$ sieve, and the wash-through soil water was collected. The minced roots were mixed with sand and applied as a thin 

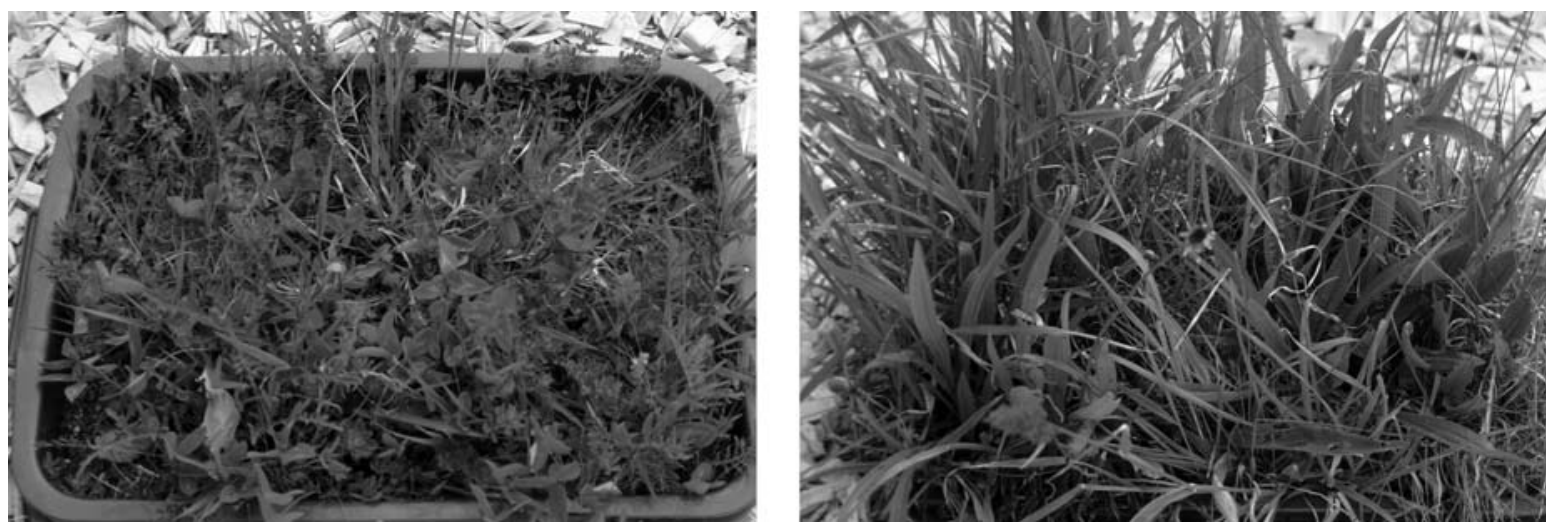

Plate 1. The extreme end points of grassland assembly: (left) species-rich vegetation of a lightly disturbed and infertile environment; (right) species poor vegetation of a stable and fertile environment. Photo credit: R. Ejrnæs.

topping on each microcosm, and the soil water was applied as liquid inoculum.

\section{Treatments}

We manipulated the physical environment (soil and climate), the productivity, the disturbance, and the colonization sequence during the experiment.

The soil/climate treatment was motivated by the finding of a complex soil/microclimate gradient as the major gradient in a multivariate analysis of Danish grassland vegetation (Ejrnæs and Bruun 2000). The two levels were moist/organic (Mo) and dry/mineral (Dm). The Mo treatment was created by mixing the sand with $20 \%$ (by volume) of moist peat, and the Dm treament was created by mixing glaciolacustrine clay (3\% by volume) and commercial chalk (5\% by volume) into the sand. The clay constituted $90 \%$ clay minerals and the chalk was $77 \% \mathrm{CaCO}_{3}$. The Dm microcosms where placed on a wind-exposed upper part of a south-facing slope, while the Mo microcosms were placed in a sheltered depression north of a forest edge, providing a relatively damp microclimate.

The nutrient treatment included a fertile $(+\mathrm{N})$ and an infertile state $(-\mathrm{N})$. The fertile state compared to fertilized agricultural grasslands. Nutrients were added as a complete commercial liquid fertilizer three times during the first growing season in May, June, and July, in equal doses adding up to $16.5 \mathrm{~g} \mathrm{~N} / \mathrm{m}^{2}, 2.7 \mathrm{~g} \mathrm{P} / \mathrm{m}^{2}$, and $12.9 \mathrm{~g} \mathrm{~K} / \mathrm{m}^{2}$. In order to stimulate the establishment, the infertile treatment included one minor fertilizer dose following seed germination in June corresponding to $0.37 \mathrm{~g} \mathrm{~N} / \mathrm{m}^{2}, 0.06 \mathrm{~g} \mathrm{P} / \mathrm{m}^{2}$, and $0.29 \mathrm{~g} \mathrm{~K} / \mathrm{m}^{2}$. In subsequent years, nutrients were applied annually in April to the fertile treatment only as commercial solid fertilizer at doses corresponding to $12.6 \mathrm{~g} \mathrm{~N} / \mathrm{m}^{2}, 2.7 \mathrm{~g} \mathrm{P} / \mathrm{m}^{2}$, and $16 \mathrm{~g}$ $\mathrm{K} / \mathrm{m}^{2}$.

The defoliation treatment included an uncut $(-\mathrm{C})$ and a cut state $(+\mathrm{C})$. We applied a monthly cutback of all plant parts projecting more than $4 \mathrm{~cm}$ above the soil surface during the growing season from April to
October, but not starting before July in the first year. The clippings were removed from the microcosms, dried, and weighed.

We worked with two groups of 24 species each. We used previous numerical analyses on large data sets from Danish grassland vegetation (Ejrnæs and Bruun 2000, Ejrnæs et al. 2002, 2004) to select these species to be either specialist species confined to seminatural grassland habitats or opportunistic species occurring in a wide range of open habitats of the nutrient-polluted and frequently disturbed agricultural landscape (Appendix B). The specialist group (S) included a high proportion of stress-tolerant perennials and the opportunist group (O) included a larger proportion of annuals and potentially tall and competitive species. The species were selected to result in similar seed mass and life form distributions for the two groups (Appendix B).

We added 30 seeds of each species to each microcosm. In half of the microcosms, the specialists were added in 1998 and the opportunists in 1999. In the other half, the colonization sequence was reversed. In the establishment year of 1998, due to limited availability of seeds, 12 species were added 20 May while the remaining 12 species were added 15 September. In 1999 all 24 remaining species were added 5 September.

The seeds were collected in 1997 (the spring species) and 1998 (the autumn species) in the local agricultural landscape around Kalø and in the seminatural grassland areas of Mols and Helgenæs. Seeds were air dried and kept at $5^{\circ} \mathrm{C}$. We only included seeds without signs of predation that either readily germinated or at least imbibed $(>50 \%)$ on wet filter paper in the laboratory prior to seeding.

In the establishment phase in May-July 1998, we watered whenever the surface was dry. In the remaining period, we watered with $10 \mathrm{~mm}$ tap water twice per week during dry periods in July and August. Despite this, the microcosms experienced periods of drought in 1999 and 2000 , more pronounced in the Dm treatment than in the Mo treatment. Loss of plant turgor appeared first in the 
$+\mathrm{N}$ treatment, it being the most water consuming. We continually removed seedlings of species alien to the experiment, but should add that this spontaneous colonization constituted a very small proportion of the observed seedlings in the microcosms.

\section{Recording of species}

A rectangular grid was placed over each box dividing it in $5 \times 8$ subplots $(4.5 \times 5.2 \mathrm{~cm})$, and the presence of species in each subplot was recorded in September 1998, July 1999, and July 2000, with only the two last censuses being used in this study. The appearance of the vegetation prior to sampling in 2000 can be seen in Appendix A.

\section{Data analysis}

We used Student's $t$ test to test for differences in seed mass, maximum height, Grime's strategy spectra (Grime 1979, Ejrnæs and Bruun 2000), and overall frequency in microcosms of species from the two species groups. The ratio of mean single-species frequency in subplots to the frequency sum of all species in a particular treatment combination was used as index of dominance. We considered species that constituted at least $15 \%$ of all species recordings in microcosm subplots of a particular treatment combination as dominants.

We used ANOVA to investigate the effect of all treatments and interactions on species richness. The per microcosm and the per subplot species numbers were highly correlated $(r=0.9)$, and as our analyses did not reveal any difference in the rank order of the main effects of the ANOVA, we chose to use species number per microcosm for the analyses of variation in richness.

We analyzed the invasion process by ANCOVA aiming at a prediction of the number of species added in the second year and surviving until the recording in the third year. We would expect the number of invaders to depend on (1) a species pool effect defined as the differential adaptation of the two invading species groups to the experimental environment (soil volume, water availability, etc.), (2) the experimental treatments, (3) the richness of the established vegetation (founder species) at the time of seeding, and (4) remaining effects determined by the confrontation between established and invading species given environment. As measure of adaptation, we used the mean richness of each of the two species groups in the microcosms as recorded in July 1999. As a measure of the resident species richness facing the invaders, we used the number of founder species recorded in July 1999 prior to seeding of invaders. Finally, we fit the residual effect of founders meeting invaders by introducing all interactions between the three environmental treatments and colonization sequence. The predictor variables were added sequentially in the ANCOVA with species adaptation entering first, followed by environmental treatments, founder richness, and ending with the interactions between sequence and environment.
The analysis of treatment effects on species composition was investigated by condensing the species $\times$ microcosm matrix by ordination, followed by analysis of variance. We used the frequency data as input and two ordination methods: nonmetric multidimensional scaling with 1000 random configurations of $1-3$ axes and detrended correspondence analysis (DCA). We selected DCA as the preferred method based on a higher correlation between the pairwise distances in the dissimilarity matrix and the corresponding distances in ordination space (McCune and Grace 2002). As a dissimilarity measure we used the Czekanowski index (i.e., Sørensen distance in quantitative form). Following ordination, we applied analysis of variance to ordination scores of microcosms looking for effects of treatments and their interactions. In order to compare the microcosm vegetation with natural communities, we applied DCA to a composite data set including two random replicates of each of the 16 treatments and 504 vegetation plots from grass field, old field, and grassland habitats of the Danish countryside, a habitat-based selection of the data set of Ejrnæs et al. (2002).

Normality and variance homogeneity of residuals in ANOVA and ANCOVA were checked using diagnostic plots (Crawley 2004). Ordination and correlation with the dissimilarity matrix was calculated in PC-Ord (McCune and Mefford 1999), and the remaining analyses were run in S-Plus 6.1 (Insightful Corporation, Seattle, Washington, USA).

\section{RESUlts}

With the exception of two annual species from each species group, all species were observed (beyond seedling stage) in the microcosms (Appendix B). At the end of the experiment another four opportunists and two specialists were no longer present, five of these being annuals. Across the whole experiment the specialist species were more successful colonizers, but due to a high withingroup variation in frequency, this difference was only marginally significant in a $t$ test $(P=0.051)$.

The most frequent species across all treatments were forbs such as Geranium sanguineum (118 microcosms), Ranunculus bulbosus (115), Rumex acetosa (111), and Plantago lanceolata (101), but some grasses were also frequent: Bromus erectus (109), Lolium perenne (99), and Dactylis glomerata (91) (nomenclature follows Tutin et al. [1964-1980]; Appendix B). The most dominant species in specific treatment combinations were generally grasses (Appendix C), with seven species representing $>15 \%$ of all subplot recordings in one or more treatment combinations: Festuca rubra, Dactylis glomerata, Lolium perenne, Plantago lanceolata, Rumex acetosa (opportunists), Festuca ovina, and Agrostis capillaris (specialists). The dominance index further revealed that dominance of one or a few species occurred in all fertile microcosms, whereas only Festuca rubra was able to attain a consistently high mean frequency ratio under infertile conditions also. Only species that colonized in spring the 
TABLE 1. ANOVA table of treatment effects on species richness and species composition (plot scores from detrended correspondence analysis [DCA] ordination).

\begin{tabular}{|c|c|c|c|c|c|c|}
\hline \multirow[b]{2}{*}{ Treatment } & \multicolumn{3}{|c|}{ Response $=$ richness } & \multicolumn{3}{|c|}{ Response $=$ composition } \\
\hline & $F$ & $P$ & $\mathrm{SS} \%$ & $F$ & $P$ & SS $\%$ \\
\hline Nutrients & 710 & $<0.001$ & 46 & 2 & 0.20 & 0.0 \\
\hline Defoliation & 291 & $<0.001$ & 19 & 27 & $<0.001$ & 0.1 \\
\hline Soil/climate & 125 & $<0.001$ & 8 & 21 & $<0.001$ & 0.1 \\
\hline Nutrients $\times$ defoliation & 31 & $<0.001$ & 2 & 0 & 0.7769 & 0.0 \\
\hline Nutrients $\times$ soil/climate & 5 & 0.02 & $<1$ & 12 & $<0.001$ & 0.0 \\
\hline Defoliation $\times$ soil $/$ climate & 0.9 & 0.35 & $<1$ & 1 & 0.41 & 0.0 \\
\hline Nutrients $\times$ defoliation $\times$ soil $/$ climate & 54 & $<0.001$ & 3 & 5 & 0.02 & 0.0 \\
\hline Sequence & 110 & $<0.001$ & 7 & 28821 & $<0.001$ & 96.4 \\
\hline Sequence $\times$ nutrients & 8 & 0.0049 & 1 & 542 & $<0.001$ & 1.8 \\
\hline Sequence $\times$ defoliation & 22 & $<0.001$ & 1 & 201 & 0.001 & 0.7 \\
\hline Sequence $\times$ soil/climate & 21 & $<0.001$ & 1 & 65 & $<0.001$ & 0.2 \\
\hline Sequence $\times$ nutrients $\times$ defoliation & 12 & $<0.001$ & 1 & 17 & 0.0001 & 0.1 \\
\hline Sequence $\times$ nutrients $\times$ soil $/$ climate & 2 & 0.22 & $<1$ & 1 & 0.33 & 0.0 \\
\hline Sequence $\times$ defoliation $\times$ soil $/$ climate & 0.4 & 0.54 & $<1$ & 0 & 0.50 & 0.0 \\
\hline Sequence $\times$ defoliation $\times$ nutrients $\times$ soil $/$ climate & 16 & $<0.001$ & 1 & 30 & $<0.001$ & 0.1 \\
\hline Residuals & & & 9 & & & 0.5 \\
\hline
\end{tabular}

Notes: Environmental effects are grouped in the upper part of the table, and effects involving colonization sequence in the lower half of the table. The two ANOVAs including significant terms only $(P<0.05)$ have $r^{2}=0.91$ (richness) and $r^{2}=0.995$ (composition). ss $\%$ is the sum of squares explained by a given term in the model as a percentage of the total sum of squares, including the residuals. The research was conducted in Kalø, Eastern Jutland, Denmark.

first year were able to achieve dominance. Cutting reduced the frequency ratio of dominant species in the fertile treatment, except for L. perenne, which only occurred as dominant after defoliation. The Dm treatment seemed to invoke a certain degree of dominance, when infertile and uncut, by F. rubra, D. glomerata, $P$. lanceolata, and $R$. acetosa (Appendix C). Dominance coincided with high productivity, reflected by the yield after defoliation in 1999-2000 varying greatly from $38 \mathrm{~g} /$ $\mathrm{m}^{2}$ in specialist-first, moist/organic, and infertile microcosms to $1203 \mathrm{~g} / \mathrm{m}^{2}$ in opportunist-first, dry/mineral, and fertile microcosms and with opportunists producing three times the yield of specialists under fertile conditions and 4-9 times the yield under infertile conditions (Appendix C).

\section{Species richness}

Species richness was most strongly affected by environment as represented by nutrients, defoliation, and soil/climate (Table 1, Fig. 1). Nutrients explained by far the largest proportion of variation, followed by defoliation and soil/climate. Together, environmental treatments and interactions explained $>79 \%$ of the variation in richness. Although highly significant,

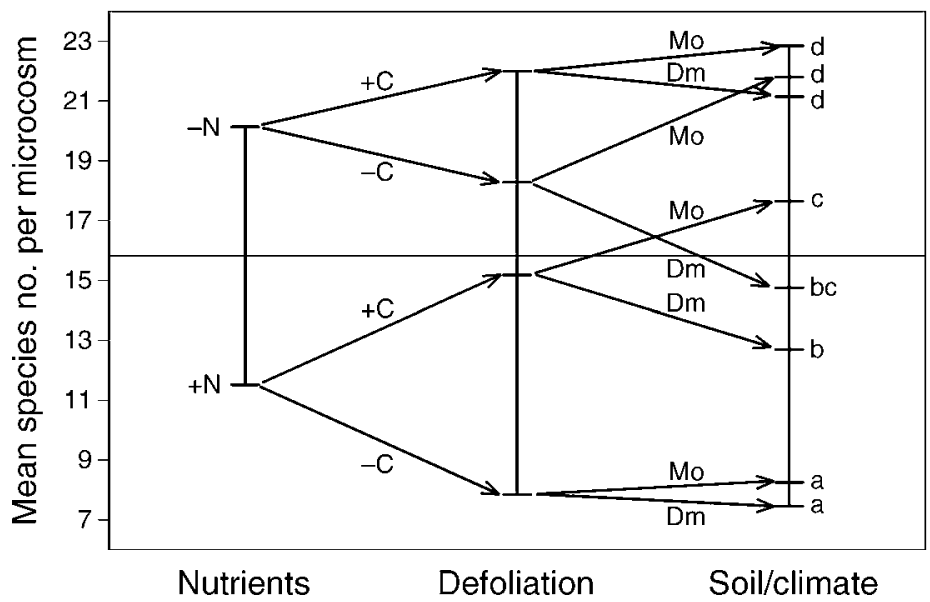

FIG. 1. Design plot showing mean species number for the levels of and the interactions between nutrients $(+\mathrm{N}$, fertile; $-\mathrm{N}$, infertile), defoliation ( $+\mathrm{C}$, cut; $-\mathrm{C}$, uncut), and soil/climate (Mo, moist/organic; Dm, dry/mineral) in decreasing importance in ANOVA. The horizontal line indicates the overall mean species number. Arrows combine the treatments in their respective interactions. All differences in means corresponding to level of nutrients and its interactions with defoliation were significant, whereas significance between levels of the third-order interaction is indicated by small letters (Tukey's hsd, $P<0.05$ ). The research was conducted in Kalø, Eastern Jutland, Denmark. 
TABLe 2. ANCOVA of the effects of species pool size, environment, species richness, and the interaction between species groups and environment on the number of successful invader species.

\begin{tabular}{lrrcr}
\hline \hline \multicolumn{1}{c}{ Treatment } & ss & \multicolumn{1}{c}{$F$} & $P$ & SS $\%$ \\
\hline Species pool size & 116 & 60 & $<0.001$ & 8 \\
Environment & & & & \\
$\quad$ Nutrients & 410 & 212 & $<0.001$ & 29 \\
$\quad$ Defoliation & 235 & 122 & $<0.001$ & 17 \\
$\quad$ Soil/climate & 148 & 77 & $<0.001$ & 11 \\
$\quad$ Nutrients $\times$ defoliation & 6 & 3 & 0.071 & 0 \\
$\quad$ Nutrients $\times$ soil/climate & 14 & 7 & 0.007 & 1 \\
$\quad$ Defoliation $\times$ soil/climate & 4 & 2 & 0.14 & 0 \\
$\quad$ Nutrients $\times$ defoliation & 73 & 38 & $<0.001$ & 5 \\
$\quad \times$ soil/climate & & & & \\
Founder species richness & 3 & 2 & 0.21 & 0 \\
Sequence $\times$ nutrients & 25 & 13 & $<0.001$ & 2 \\
Sequence $\times$ defoliation & 70 & 36 & $<0.001$ & 5 \\
Sequence $\times$ soil/climate & 18 & 9 & 0.003 & 1 \\
Residuals & 276 & & & 20 \\
\hline
\end{tabular}

Note: Model $r^{2}$ was 0.80 .

colonization sequence only explained $7 \%$ of the variation in richness rising to $12 \%$ when all significant interactions with environment were included (Table 1). Nutrient addition led to declining richness, whereas defoliation generally promoted richness. The Dm treatment was generally less species-rich than the Mo treatment (Fig. 1). The S-first colonization resulted in slightly more species than the O-first (Table 1). There was no effect of treatment blocks (not included in table). The interactions were weaker than the main effects (Table 1), but it is worth noting the significant secondorder interactions between nutrients and defoliation and the corresponding third-order interaction with soil/ climate. The largest effect of defoliation was observed after nutrient addition, and the largest effect of soil/ climate was observed in microcosms of intermediate richness and biomass (either $+\mathrm{N} /+\mathrm{C}$ or $-\mathrm{N} /-\mathrm{C}$; Fig. 1).

\section{Invasibility}

The specialist group appeared better adapted to the general experimental environment as they contributed with an average pool of 15.8 established species in July 1999, whereas the opportunists only contributed with 10.3 species. This difference was consistent also in the invasion process with 4.2 specialist and 2.5 opportunist invaders on average, and it explained $8 \%$ of the variation in number of invaders $(P<0.001$, Table 2$)$. Nutrients, defoliation, soil/climate, and their interactions accounted for almost $63 \%$ of the variation in number of invading species (Table 2). No block effect was seen (not shown). There was no significant effect of founder richness after fitting of species pool and environment (Table 2). If, however, we introduced species richness in the model before environmental treatments, we found a highly significant and positive effect of richness on invasibility (ss $\%=19, P<0.001)$.
We found significant effects of the second-order interactions between environmental treatments and colonization sequence (cumulative ss $\%=8$ ). This indicates a significant interaction between founder/ invader group and environment, which could not be accounted for by the richness of founders, the effect of the environment, and the adaptation of invaders.

\section{Species composition}

Detrended correspondence analysis (DCA) explained as much as $95.7 \%$ of variation in the dissimilarity matrix on the first ordination axis with only $1.1 \%$ expressed on the second axis. We selected the first DCA axis for further analysis. The treatments and their interactions explained no less than $99.5 \%$ of the variation in DCA scores. All treatments had significant effects on species composition either alone or in combination (Table 1). Arrival order was by far the most influential treatment, explaining $96.4 \%$ of the variation (Table 1, Fig. 2) and producing two clusters of communities, one resembling dry, seminatural grassland vegetation, the other transitional to more nutrient-rich vegetation of the agricultural landscape (Appendix D). The interaction between sequence and nutrients was the second-most influential $(1.8 \%)$, followed by the interaction with defoliation $(0.7 \%)$. In general, floristic distance between treatments involving $\mathrm{O}$-first and S-first increased with fertilization and decreased with defoliation (Fig. 2). In the ordination of microcosms with natural communities the two first DCA axes were interpreted as a nutrient gradient and a soil $\mathrm{pH}$ gradient, respectively, based on strong correlations between axes' scores and weighted averages for the plots of Ellenberg numbers for species preferences (Ellenberg et al. 1992). The overall pattern of the experiment was reproduced in the ordination, with microcosms placed in two clusters with O-first lying closer to old fields and grass fields and S-first being more grassland-like (Appendix D).

\section{DisCUSSION}

Our experiment provides empirical evidence for strong environmental control over species richness and invasibility in the assembly of grassland vegetation. Although arrival order of species affected species richness significantly, the variance explained was small compared to environmental treatments. We suggest that the effect of arrival order on richness may be largely due to the fact that the specialist group contained more species adapted to our particular environmental regime, wherefore the specialist-first treatment came out as the most species-rich at the end of the experiment. The analyses of richness and invasibility revealed almost similar importance ranking of environmental effects. So, although most of the species in the microcosms established in the first season, without competition from established vegetation, the colonization in the second year appeared to follow the same environmental assembly rules with most successful invaders in infertile 


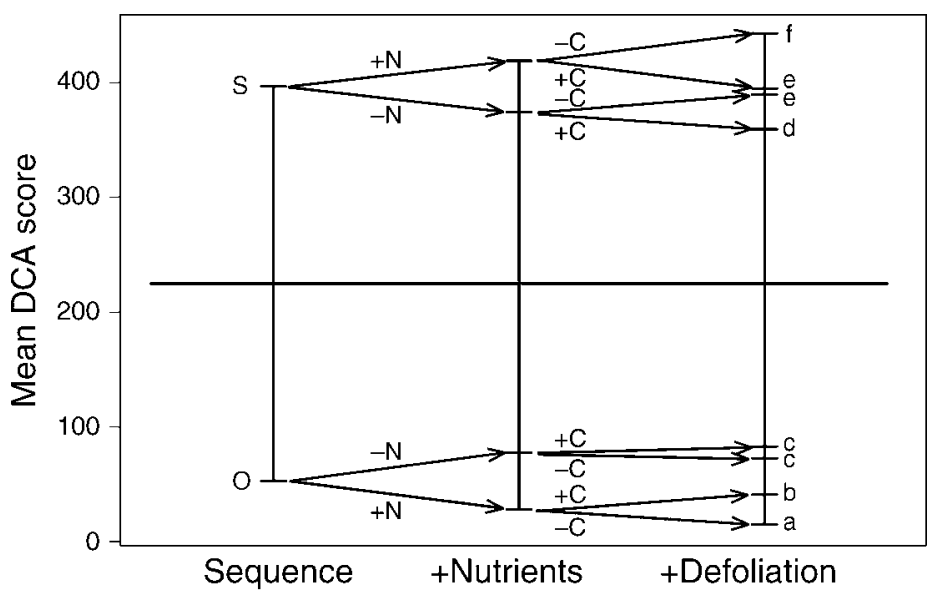

FIG. 2. Design plot showing mean score on the first detrended correspondence analysis (DCA) ordination axis for the levels of sequence and the interactions between sequence $(\mathrm{O}$, opportunist; $\mathrm{S}$, specialist), nutrients $(+\mathrm{N}$, fertile; $-\mathrm{N}$, infertile), and defoliation $(+\mathrm{C}$, cut; $-\mathrm{C}$, uncut $)$ in decreasing importance in ANOVA. The horizontal line indicates the overall mean DCA score. Arrows combine the treatments in their respective interactions. Differences in means between sequence and its interaction with nutrient levels were all significant. Significant differences between levels of the third-order interactions are indicated by lowercase letters (Tukey's hsd, $P<0.05$ ).

and cut microcosms, coinciding with a species-rich founder vegetation. In this experiment, we cannot assess the spontaneous colonization of vascular plants as these were weeded in order to control the colonization process. However, Aude and Ejrnæs (2005) analyzed the spontaneous colonization by bryophytes in a subset of the microcosms and found significantly more colonizers in infertile and cut microcosms.

Our interpretation that richness and invasibility are controlled by the same environmental factors is in agreement with a number of recent studies (Davis et al. 2000, Davis and Pelsor 2001, Foster et al. 2002), but seems contrary to studies reporting a positive effect of diversity on resistance to invasion (e.g., Kennedy et al. 2002). The apparent disagreement may be resolved if we acknowledge that a significant negative effect of richness on invasibility within a given environmental setting does not exclude a positive correlation between richness and invasibility along an environmental gradient.

The importance rank of environment and arrival order was reversed in the case of species composition, with differential arrival order leading to two compositionally different clusters of microcosms irrespective of environmental treatments (Fig. 2, Appendix D). Besides this pervasive effect, we also observed significant effects of defoliation, soil/climate, and the interactions between sequence on one side and nutrients, defoliation, and soil/ climate on the other. Differential arrival order may thus lead to different compositional equilibria. Moreover, our results (Fig. 2) support the hypothesis that the probability of multiple equilibria should increase with increasing productivity and environmental stability (Chase 2003). While Chase emphasizes the role of differential species pools, our study shows that recruitment limitation due to increased asymmetric competition in fertile and undis- turbed microcosms can also prevent the convergence of species composition in similar environments.

A short-duration experiment with synthetic communities has obvious limitations. Natural communities have had centuries to approach an equilibrium between environment and species composition and experience seasonal and annual variation in environmental conditions as well as interactions with other trophic levels. On the other hand, the merits of controlled microcosms include the opportunity for quantitative assessments of the effects and interactions of single factors that are otherwise heavily obscured by the multivariate nature and strong historical contingency of natural communities (Fraser and Keddy 1997).

It may be argued that the short duration of the experiment obstructs the floristic convergence that would eventually take place given a continued input of propagules of a wide range of functional types. On the other hand, the vast majority of seeds of grassland plants are dispersed no more than a few meters from the mother plant (Harper 1977), and therefore a once-established set of species is likely to dominate the seed rain and thus maintain itself. This interpretation is consistent with long-term studies (Milchunas and Lauenroth 1995) and field observations (Ozinga et al. 2005), indicating that historical contingency and dispersal limitation may lead to compositional inertia and considerable variation in the response to environmental variation.

A core assumption of the unified neutral theory of diversity is the functional equivalence of species within a trophic level (Hubbell 2001, 2005). Neutral theory does not preclude niche differences among species, but questions their importance for community assembly. Our results indicate a high level of species redundancy. Although we see significant differences in functional attributes between specialists and opportunists, the 
outcome in terms of species composition depended largely on historical contingency (arrival order) and not so much on the known habitat affiliation and traits of the species. Indeed, we found species dominating in unexpected environments when judged by their functional traits and known habitat preference. Likewise, richness and invasibility depended largely on environmental regime and not so much on the traits of the constituent species. Even competitively subordinate species, such as Agrostis capillaris and Festuca ovina, producing only one-third of the yield of opportunists in fertile microcosms, achieved high dominance under fertile conditions when arriving first. Common assembly mechanisms in the first years of succession thus appeared to overrule the niche differences of species. But, while the unified neutral theory assumes that local mechanisms such as competitive exclusion are not needed in order to explain diversity, our results indicate that the driving mechanism producing variation in species numbers is the strength of competitive asymmetry, i.e., the degree to which established plants exclude seedlings.

Proponents of neutral theory often attribute a separate effect on diversity to the size of mature individuals (Hubbell 2001, Aarssen 2004), and it is true that individuals were generally larger in the fertile, uncut microcosms. We do, however, find this explanation less satisfactory as it ignores the ecological mechanism by which seeded species are denied recruitment.

In contrast to the prediction of neutral theory, we found a significant effect of arrival order on richness. And despite considerable functional equivalence with regard to richness and invasibility, species composition and relative abundance were clearly nonrandom with marked between-treatment and very little within-treatment variation. Thus, while it seems justified to predict low diversity and dominance of a few species given fertile and stable conditions, it will only be possible to predict who will win and who will lose based on detailed consideration of the match between the niches of the species and the environmental regime. This may appear less important for the analysis of patterns in diversity, but could be essential for the conservation of rare species, prediction of alien invasions, and forecasting of biotic responses to global change.

\section{ACKNOWLEDGMENTS}

This project was made possible through a grant to first author from The Danish Forest and Nature Agency. Four anonymous referees are thanked for thoughtful and stimulating comments and suggestions.

\section{Literature Cited}

Aarssen, L. W. 2004. Interpreting co-variation in species richness and productivity in terrestrial vegetation: making sense of causations and correlations at multiple scales. Folia Geobotanica 39:385-403.

Aude, E., and R. Ejrnæs. 2005. Bryophyte colonisation in experimental microcosms: the role of nutrients, defoliation and vascular vegetation. Oikos 109:323-330.

Chase, J. M. 2003. Community assembly: When should history matter? Oecologia 136:489-498.
Connell, J. H. 1978. Diversity in tropical rain forests and coral reefs. Science 199:1302-1310.

Crawley, M. J. 2004. Statistical computing. An introduction to data analysis using S-Plus. John Wiley and Sons, Chichester, UK.

Davis, M. A., J. P. Grime, and K. Thompson. 2000. Fluctuating resources in plant communities: a general theory of invasibility. Journal of Ecology 88:528-534.

Davis, M. A., and M. Pelsor. 2001. Experimental support for a resource-based mechanistic model of invasibility. Ecology Letters 4:421-428.

de Deyn, G. B., C. E. Raaijmakers, H. R. Zoomer, M. P. Berg, P. C. de Ruiter, H. A. Verhoef, T. M. Bezemer, and W. H. van der Putten. 2003. Soil invertebrate fauna enhances grassland succession and diversity. Nature 422:711-713.

Diamond, J. M. 1975. Assembly of species communities. Pages 342-444 in M. L. Cody and J. M. Diamond, editors. Ecology and evolution of communities. Harvard University Press, Cambridge, Massachusetts, USA.

Ejrnæs, R., E. Aude, B. Nygaard, and B. Münier. 2002. Prediction of habitat quality using ordination and neural networks. Ecological Applications 12:1180-1187.

Ejrnæs, R., and H. H. Bruun. 2000. Gradient analysis of dry grassland vegetation in Denmark. Journal of Vegetation Science 11:573-584.

Ejrnæs, R., H. H. Bruun, E. Aude, and E. Buchwald. 2004. Developing a classifier for the Habitats Directive grassland types in Denmark using species lists for prediction. Applied Vegetation Science 7:71-80.

Ellenberg, H., H. E. Weber, R. Düll, V. Wirth, W. Werner, and D. Paulissen. 1992. Zeigerwerte von Pflanzen in Mitteleuropa. Scripta Geobotanica 18. Verlag E. Goltze KG, Göttingen, Germany.

Foster, B. L., V. H. Smith, T. L. Dickson, and T. Hildebrand. 2002. Invasibility and compositional stability in a grassland community: relationship to diversity and extrinsic factors. Oikos 99:300-307.

Fraser, L. H., and P. A. Keddy. 1997. The role of experimental microcosms in ecological research. Trends in Ecology and Evolution 12:478-481.

Grime, J. P. 1973a. Competitive exclusion in herbaceous vegetation. Nature 242:344-347.

Grime, J. P. 1973b. Control of species density in herbaceous vegetation. Journal of Environmental Management 1:151167.

Grime, J. P. 1979. Plant strategies and vegetation processes. John Wiley and Sons, Chichester, UK.

Grime, J. P., J. M. L. Mackey, S. H. Hillier, and D. J. Read. 1987. Floristic diversity in a model system using experimental microcosms. Nature 328:420-422.

Harper, J. L. 1977. Population biology of plants. Academic Press, London, UK.

Hubbell, S. P. 2001. The unified neutral theory of biodiversity and biogeography. Princeton University Press, Princeton, New Jersey, USA.

Hubbell, S. P. 2005. Neutral theory in community ecology and the hypothesis of functional equivalence. Functional Ecology 19:166-172.

Huston, M. A. 1994. Biological diversity: the coexistence of species on changing landscapes. Cambridge University Press, Cambridge, UK.

Keddy, P., L. Twolan-Strutt, and B. Shipley. 1997. Experimental evidence that interspecific competitive asymmetry increases with soil productivity. Oikos 80:253-256.

Kennedy, T. A., S. Naeem, K. M. Howe, J. M. H. Knops, D. Tilman, and P. Reich. 2002. Biodiversity as a barrier to ecological invasion. Nature 417:636-638.

McCune, B., and T. F. H. Allen. 1985. Will similar forests develop on similar sites? Canadian Journal of Botany 63:367376. 
McCune, B., and J. B. Grace. 2002. Analysis of ecological communities. MjM Software, Gleneden Beach, Oregon, USA.

McCune, B., and M. J. Mefford. 1999. Multivariate analysis of ecological data. Version 4.25. MjM Software, Gleneden Beach, Oregon, USA.

Milchunas, D. G., and W. K. Lauenroth. 1995. Inertia in plant community structure: state changes after cessation of nutrient-enrichment stress. Ecological Applications 5:452458.

Mittelbach, G. G., C. F. Steiner, S. M. Scheiner, K. L. Gross, H. L. Reynolds, R. B. Waide, M. R. Willig, S. I. Dodson, and L. Gough. 2001. What is the observed relationship between species richness and productivity? Ecology 82:2381-2396.

Ozinga, W. A., J. H. J. Schaminée, R. M. Bekker, S. Bonn, P. Poschlod, O. Tackenberg, J. Bakker, and J. M. van Groenendael. 2005. Predictability of plant species composition from environmental conditions is constrained by dispersal limitation. Oikos 108:555-561.

Pärtel, M., M. Zobel, K. Zobel, and E. van der Maarel. 1996. The species pool and its relation to species richness: evidence from Estonian plant communities. Oikos 75:111-117.
Spehn, E. M., et al. 2005. Ecosystem effects of biodiversity manipulations in European grasslands. Ecological Monographs 75:37-63.

Stevens, M. H. H., D. E. Bunker, S. A. Schnitzer, and W. P. Carson. 2004. Establishment limitation reduces species recruitment and species richness as soil resources rise. Journal of Ecology 92:339-347.

Svenning, J.-C., D. A. Kinner, R. F. Stallard, B. M. J. Engelbrecht, and S. J. Wright. 2004. Ecological determinism in plant community structure across a tropical forest landscape. Ecology 85:2526-2538.

Tutin, T. G., et al. 1964-1980. Flora Europaea. Cambridge University Press, Cambridge, UK.

Weiher, E., S. Forbes, T. Schauwecker, and J. B. Grace. 2004. Multivariate control of plant species richness and community biomass in blackland prairie. Oikos 106:151-157.

Zobel, M. 1997. The relative role of species pools in determining plant species richness: an alternative explanation of species coexistence. Trends in Ecology and Evolution 12: 266-269.

\section{APPENDIX A}

Photographs showing the appearance of microcosms in the dry-mineral site in June 2000 (Ecological Archives E087-072-A1).

\section{APPENDIX B}

A summary of the 48 study species (Ecological Archives E087-072-A2).

\section{APPENDIX C}

A table showing dominant species and yield from cutting presented by treatments (Ecological Archives E087-072-A3).

\section{APPENDIX D}

A figure showing the comparison of microcosm communities with real communities (Ecological Archives E087-072-A4). 